\title{
MIGRACIÓN Y MOVILIDAD MAPUCHE A LA PATAGONIA ARGENTINA ${ }^{1}$.
}

\author{
HANS GUNDERMANN*, HÉCTOR GONZÁLEZ* Y LARISA DE RUYT
}

\begin{abstract}
RESUMEN
El artículo presenta antecedentes acerca de la migración y movilidad campesina y mapuche desde las regiones de La Araucanía, Los Ríos y Los Lagos a la Patagonia argentina, especialmente al Neuquén y Río Negro, durante la segunda mitad del siglo XX, como parte de un proceso mucho más amplio de redistribución espacial que incluye el centro de Chile, Magallanes y la Patagonia trasandina. Se describen sus características y los cambios que en ella han tenido lugar, tanto por los vaivenes de las economías y las relaciones entre Chile y Argentina, como por la persistencia y transformación de redes sociales de parentesco y comunalidad entre áreas de origen y de destino. Lo anterior se pone en relación con la pauta de integración regional que el pueblo mapuche ha construido en la época moderna y las relaciones translocalizadas que siguen favoreciendo una notable movilidad, vinculando sus segmentos rurales y urbanos, peri o semi urbanos.
\end{abstract}

PALABRAS CLAVES: pueblo mapuche, migración, movilidad, translocalización, Patagonia

\section{MAPUCHE MIGRATION AND MOBILITY TO ARGENTINIAN PATAGONIA}

\section{ABSTRACT}

This article offers background information on the migration and mobility of peasants and Mapuche people from the Araucanía, Los Rios and Los Lagos regions to the Argentinian Patagonia, especially to

1 Proyecto Fondecyt $N^{\circ} 1060973$ "Comunidades translocales: grupos y redes sociales indígenas en un contexto de postcomunalidad". Una versión resumida de este artículo fue presentada como ponencia en el IX Congreso Argentino de Antropología Social, Simposio "Movimientos indígenas, políticas indigenistas y academias en Pampa, Patagonia y Araucanía: comparaciones nacionales y regionales entre Chile y Argentina", Coordinadores Dra. Claudia Briones (UBA), Dr. Hans Gundermann (UCN), Dra. Ana Ramos (UBA), Posadas, Misiones, Argentina, 5 al 8 de agosto de 2008.

* Antropólogo, Doctorado en Sociología, profesor e investigador en el Instituto de Investigaciones Arqueológicas y Museo (IIAM), Universidad Católica del Norte, Calle Gustavo Le Paige 380, San Pedro de Atacama, correo electrónico: hgunder@ucn.cl

- Antropólogo, con estudios de Doctorado en Historia por la Universidad de Barcelona, profesor e investigador en el Departamento de Antropología de la Universidad de Tarapacá, 18 de Septiembre 2222, casilla 6-D, Arica, correo electrónico: hgonzale@uta. cl.

* Antropóloga, investigadora adscrita al Proyecto Fondecyt N¹060973, Calle Gustavo Le Paige 380, San Pedro de Atacama, correo electrónico: lderuyt@yahoo.com 
Neuquén and Río Negro, during the second half of the $20^{\text {th }}$ century. This event is part of a larger process of spatial redistribution that includes central Chile, Magallanes and the Patagonia region across the Andes. We describe this economic migration as well as the changes that have taken place because of the oscillation of economies and the relations between Chile and Argentina, or because of the persistence and transformation of kinship and community social nets between the areas of origin and destination. This idea is related to the regional integration pattern that the Mapuche people have created in the modern era as well as to the translocated relationships that keep favoring mobility between its rural, urban and semi urban components.

KEYWORDS: Mapuche People, migration, mobility, trans location, Patagonia

\section{INTRODUCCIÓN}

Los pueblos indígenas de Chile están viviendo transformaciones de gran envergadura. Tales cambios pueden describirse mediante la noción de postcomunalidad y se refieren a las emigraciones y movilidad que protagonizan, a un patrón de ingresos menos dependiente de fuentes agrarias que antaño, al aumento del trabajo asalariado a distancia y a una drástica ampliación de los espacios sociales en que se participa. Ello impacta en una medida importante a la sociedad mapuche del sur de Chile y, con variantes, a otros pueblos indígenas del país (aymaras, atacameños, quechuas o rapanuis). Durante las últimas tres décadas, estas transformaciones reciben un impulso decisivo de la integración económica y apertura comercial al exterior, de la expansión minera transnacionalizada y, dicho en términos más amplios, del proceso de modernización acelerado que vive Chile. Con todo ello las agriculturas tradicionales indígenas y la propia vida rural y campesina se han visto fuertemente sacudidas.

Esos cambios deben entenderse en relación con patrones históricos de integración indígena a las regiones de pertenencia. Tales pautas, así como el proceso de postcomunalidad actual, son específicos a los grupos étnicos, tanto por factores internos (económicos, sociopolíticos y culturales), como por las características que adoptan regionalmente los modelos de desarrollo y las modernizaciones del último medio siglo. Asimismo, y a pesar de la hoy mayoritaria presencia indígena en medios urbanos, advertimos entre ellos la persistencia transformada de un conjunto de relaciones sociales basadas en el parentesco (consanguíneo o ritual) y el origen local rural (comunalidad, vecindad, amistad). Incidiendo desde las localidades y sujetos rurales sobre los individuos, familias y grupos urbanos o de otras áreas rurales de destino, e influyendo desde los espacios y sujetos urbanos hacia las localidades rurales, participan en la formación y reproducción de redes, grupos locales y agrupaciones translocales que componen hoy las sociedades indígenas. Estas nuevas relaciones, y aquéllas que son propias de las localidades rurales, fundan hoy su condición de sociedad.

A continuación presentamos resultados de una investigación todavía en desarrollo acerca de la importancia social de lo que hemos denominado translocalización ${ }^{2}$ de las relaciones y grupos sociales indígenas. Una oportunidad de análisis y discusión de este tema lo constituye, en el caso mapuche, la movilidad y migración al centro del país y al norte de la Patagonia argentina. Se trata de un aspecto poco estudiado de la realidad surgida de las transformaciones experimentadas por ese pueblo en años recientes. Trataremos la prevaleciente condición urbana de los mapuches contemporáneos y los procesos conducentes a ello, señalando algunas implicaciones de lo anterior para las localidades rurales. Luego abordaremos aspectos de la dinámica que viven las comunidades rurales, enfatizando su condición translocalizada. La migración campesina y mapuche a la Patagonia argentina, especialmente Neuquén y Rio Negro, representa un capítulo importante de lo anterior. Se presenta y luego analiza información acerca de la localidad mapuche de Escorial, las emigraciones, reasentamiento y movilidad que protagonizan en Chile y Argentina. Las conclusiones sintetizan los resultados e integran una perspectiva regional de análisis (pautas de integración, procesos de migración) y otra social (translocalización, redes sociales y grupos locales).

2 Vigencia, fuera o más allá de la localidad de origen, de relaciones socialmente importantes basadas en el parentesco y otros principios de integración característicos de las comunidades rurales indígenas. 


\section{LA PAUTA DE INTEGRACIÓN REGIONAL MAPUCHE Y SU REDISTRIBUCIÓN ESPACIAL MODERNA}

Considerando las relativamente más confiables cifras del Censo de 2002 (respecto de las de 1992; confróntese: Gundermann, Vergara y Foerster, 2005a y b), la mayor parte de la población de los pueblos indígenas del país radica en centros urbanos: en el total nacional representa un 68,4\%. Detallado según los tres principales pueblos indígenas de Chile, un $62,4 \%$ de la población mapuche es urbana; entre los aymaras ese porcentaje llega a un 78,5\%, mientras que entre los atacameños alcanza a un 82,8\% (INEOrígenes, 2005:18-22). A diferencia de los pueblos andinos, la residencia mapuche no sólo se concentra en ciudades grandes e intermedias, sino que también en las de pequeño tamaño. En la propia Araucanía, Los Ríos y Los Lagos, los residentes urbanos llegan a un 29,2\% del total indígena regional (INE, 2003:24; INE - Orígenes, 2005:41).

La movilidad y la migración mapuches, visibles hace más de medio siglo, se vinculan a un momento de cambio modernizador de los patrones históricos de integración a las regiones del sur de Chile. La acción combinada de la presión demográfica sobre la tierra, el deterioro de recursos productivos que desde su origen fueron relativamente escasos y la incapacidad del sistema agrario regional para absorber una población en crecimiento ${ }^{3}$ estimularon la salida a los centros industriales (Santiago y Concepción), pero también a otros destinos como la Patagonia chilena y argentina, en búsqueda de trabajo e ingresos, que fue por décadas la respuesta a que acudió la sociedad indígena para resolver la atenazante presión de la "reducción". Sus características de fuerza de trabajo con bajos niveles de escolaridad y ausencia de especialización condicionaron su inserción como mano de obra no calificada en industrias de alimentos y construcción, servicios domésticos o labores agropecuarias. Obteniendo, por lo tanto, salarios mínimos y residencia en áreas de población trabajadora, periferias urbanas y establecimientos rurales.

Un segundo impulso a la movilidad y las migraciones se agrega a la trayectoria anterior. Se

3 Tema tratado por Bengoa y Valenzuela, 1982, de nuevo por Bengoa en 1985, así como por Babarovic, Campaña, Díaz y Durán en 1997. originaría en una mayor expansión del modelo dominante de desarrollo durante las últimas décadas. Concurren el auge de la industria forestal, la reorganización del sistema de relaciones rurales como resultado de la reforma y contrarreforma agraria, los problemas de la agricultura tradicional del sur y la reconversión tecnológica en curso ante las presiones ejercidas por la apertura comercial del país. En relación con todo ello, la crisis del sistema de relaciones agrarias y de las condiciones de reproducción del campesinado en esa zona, intensifican un tipo de respuesta mapuche de dos caras: retorno a la subsistencia y migraciones ${ }^{4}$. Probablemente menos de lo primero que de lo segundo y, en cualquier caso, lo uno y lo otro complementariamente ${ }^{5}$. De esta manera, las agriculturas tradicionales mapuches y la propia vida rural y campesina se han visto intensamente implicadas. Esto se objetiva en dinámicas de desruralización, en donde aspectos relevantes de la vida económica, social y cultural mapuche ya no dependen sólo o principalmente de condiciones locales, aunque se mantenga una residencia rural o semi rural; también en desagrarización de las actividades económicas, ya que el patrón de ingresos guarda menos relación que antes con recursos y productos agropecuarios. Se advierten igualmente fuerzas dirigidas a disminuir la vigencia de los modos campesinos de organización de las unidades económicas, algo que no sólo proviene del mercado, sino que guarda una relación bastante estrecha con políticas estatales. Todo ello conduce a procesos de pauperización, diferenciación, incorporación a mercados de trabajo y, para quienes perseveran, a perfiles campesinos inestables, menos nítidos. Asimismo, los patrones de interacción y relación social, reclutamiento y conformación de grupos tienden a translocalizarse, a realizarse y depender de unidades y segmentos sociales que no agregan en igual manera y medida que antaño los contingentes de la comunidad o localidad.

Bajo estas nuevas condiciones, la movilidad y la emigración mapuche recientes no pueden sin más asimilarse a los fenómenos de desplazamiento indígena a los centros industriales ocurrido en las

$4 \quad$ Un tema abordado por Bengoa en 1996, 1997 y 2000.

5 El examen de un tercer tipo de respuesta, las movilizaciones sociales y políticas por la recuperación de tierras y territorio -insertas en un horizonte histórico más amplio que el aquí abordado- excede a los límites del presente artículo. 
décadas de 1950 y 1960. Se hacen considerablemente más complejas y dinámicas, tanto por los destinos de la movilidad como por las formas que adopta (migraciones estacionales, blancos migratorios variables, diversas frecuencias y duración de las salidas y las entradas a lo rural o lo urbano $)^{6}$. De esta manera, el pueblo mapuche es hoy crecientemente urbano, si se lo compara con una situación histórica previa de más definida estabilidad en la ruralidad, la agricultura y la condición campesina. Ha llegado a serlo mediante la salida de contingentes importantes desde las áreas campesinas y su incorporación a otras áreas rurales y a ciudades de todo tamaño en Chile y Argentina. En su conjunto, los procesos que afectan a la sociedad mapuche en las zonas tradicionales de vida, el dinamismo actual de las migraciones y su consecuencia de mayoritaria presencia urbana dan forma a una realidad de post comunalidad.

\section{GRUPOS Y RELACIONES SOCIALES INDÍGENAS: ¿DE QUÉ COMUNIDAD MAPUCHE PODEMOS HABLAR HOY?}

Las unidades sociológicas a las que las ciencias sociales, las legislaciones, el discurso burocrático y, al final, los propios sujetos indígenas terminaron por llamar "comunidades"7 han estado cambiando activamente en relación a la conformación que todavía poseían hace medio siglo. Hay indicios de que no estamos ante su progresiva disolución; más bien asistimos a su transformación. Estas entidades sociales intermedias -unidades de agregación social colectiva más extensas que los hogares- se encontrarían sujetas a una dinámica de remodulación histórica, seguramente inestable, que integra aspectos de la tradición y otros de la

6 Acerca de los inmigrantes mapuches en la ciudad, especialmente Santiago, véase el trabajo pionero de Munizaga, 1961. Ilustrativa es también la historia de un dirigente mapuche elaborada por Foerster, 1983. Más tarde, tenemos los de Aravena, 2000, 2002, 2003, Gissi, 2001, y Valenzuela, 1995. Asimismo, una importante literatura desarrollada por intelectuales mapuches se desplegó en la década de 1990 acerca de los mapuches urbanos, sus migraciones y procesos socio-culturales. Consúltese Ancán, 1994, Ancán y Calfío, 1999, Abarca, 2002, Valdés, 1997, Cuminao y Moreno, 1998, Curivil, 1999, entre los más conocidos.

7 De manera genérica, agrupaciones sociales rurales dotadas de estructuración. modernización, lo rural y lo urbano, lo agrario y la salida de lo agrario ${ }^{8}$.

Trabajos recientes aportan información e ideas que ayudan a esbozar un cuadro remozado de en qué consistirían las agrupaciones indígenas en el presente y qué es lo que ya no son. En ellos se insiste acerca de la influencia del contexto regional y nacional: ciclos económicos, políticas de apertura comercial, expansión de mercados, procesos regionales derivados, convergiendo con problemas y limitaciones internas, originarían situaciones de crisis, restricciones, a veces oportunidades y aperturas, que redundarían en cambios significativos al interior de las localidades ${ }^{9}$. Una constante de todo eso es el carácter considerablemente más extendido

8 El conocimiento de los pueblos originarios del país es heredero de una antropología de la comunidad campesino indígena. Para una discusión más amplia, continental, de éste y otros temas, véase Kearney (1996). Una presentación de estos tópicos para el caso de los pueblos andinos se encuentra en Gundermann y González (2008). Las etnografías mapuches atienden a los cambios históricos y las transformaciones debidas al contexto regional del que participan los grupos locales indígenas. Pero, a semejanza de los estudios etnográficos de los pueblos andinos en el norte del país, el énfasis permanece puesto sobre aspectos sociales, políticos y culturales internos. Las relaciones con el exterior y las emigraciones son conocidas y se les atribuye importancia, pero no son integradas de una manera fuerte en el análisis, tendiendo a permanecer subordinadas a una visión que claramente privilegia las relaciones e instituciones locales. Más recientemente irrumpen estudios con base etnográfica en los cuales la atención se centra en las relaciones, pero en clave étnica y, como era de esperar, aquellas que se mantienen con el Estado y sus instituciones (por ejemplo, Kellner, 1994; McFall, 1998; Bengoa, 1985, y Mallon, 2004 [1999]). Con todo, tales trabajos participan de la avalancha de estudios que abordan a los pueblos indígenas como actores etnopolíticos conscientes, sujetos de derechos colectivos o agentes culturales que procesan identidad y demandan reconocimiento, permaneciendo más difusa la percepción acerca de relaciones, redes y grupos que forman el substrato sociológico de lo anterior.

9 Un estudio de la primera mitad de la década de 1990 sobre la comuna de San Pedro de Atacama evidenció la escasa importancia económica de las actividades agropecuarias entre los ya pocos que se desempeñaban en este rubro en las aldeas del sector. Lo fundamental de los ingresos provenía del trabajo asalariado en la minería y los subsidios estatales (Gundermann y González, 1995). Ello no ha cambiado en la actualidad, aunque las fuentes de ingresos externos seguramente se han diversificado más. Redes familiares dispersas jugarían un papel destacado en las oportunidades de empleo y acogida de trabajadores atacameños. Las poco campesinas comunidades atacameñas estudiadas, tomadas en su conjunto, aportarían entonces funciones residenciales, de repliegue ante los vaivenes del mercado laboral y de retiro de fuerza de trabajo desahuciada. 
de los espacios sociales indígenas articulados desde o con las comunidades y localidades de origen ${ }^{10}$. En línea con ello, la economía campesina mapuche actual ha sido descrita como una actividad recesiva, de subsistencia, complementaria de recursos originados en extensivas migraciones y movilidad desde las comunidades rurales. Éstas se han transformado, eventualmente, en "áreas de refugio" y "territorios de entrada y salida" (Bengoa, 1996 y 1997). Es más que discutible la terminología que la describe, pero la observación de base resulta pertinente. Nuevamente, redes sociales que integran sujetos en zonas y ciudades distantes tendrían un papel de relevancia (Bengoa, 2000: 351, 352)11. Encontramos entonces antecedentes para poder sostener que la comunidad o la localidad no pueden entenderse hoy sino a través de las relaciones que sus miembros desarrollan en y fuera de ellas, sobre espacios sociales (laborales, parentales, de amistad, incluso religiosos) considerablemente distendidos, de alcance regional o incluso nacional e internacional. Y, en esta transformación, esas mismas relaciones -y a veces instituciones- están cambiando, redefiniendo el sentido y las funciones de comunidades y localidades para los grupos y redes sociales integrantes.

De esta manera, cada localidad indígena podría verse hoy como el resultado de una redefinición interna en el marco de procesos generales que se resuelven

10 En el extremo norte, antecedentes aymaras apuntan a la vigencia de migraciones y una intensa movilidad regional. Pero donde el elemento fuerte no es el asalariamiento, sino el trabajo por cuenta propia y la continuidad, cuando existen oportunidades para ello, en rubros de actividad agropecuaria. Las comunidades rurales pueden llegar a constituir un tipo entre otros de residencia y de actividad para unidades familiares o segmentos de ellas que se desplazan según los requerimientos de fuerza de trabajo, posibilidades de ingreso o compromisos de educación (González, 1996 y 1997a y b). Lo agrario puede en muchos casos representar un aspecto relevante de las economías indígenas, pero ello se realiza desde modos de residencia y organización interna de las unidades familiares que poco tienen ya de las formas de asentamiento y vida social presentes hasta hace unas décadas atrás en el campo andino.

11 Hasta aquí hemos insistido en los cambios que tienen lugar en las unidades de agrupación indígena rural, en la pérdida de importancia de las producciones campesinas y en su reubicación en un sistema de relaciones sociales en que el trabajo asalariado, la movilidad y las migraciones son parte integral. Reconocemos la existencia y posible importancia de otras relaciones, como las socio culturales, igualmente translocalizadas. regionalmente y que reproducen pautas de integración específicas de los pueblos indígenas a esas regiones, macro-regiones o al país. Esta redefinición origina modalidades de nueva ruralidad, si apreciamos los segmentos con una permanencia visible o residencia en las áreas indígenas, y comunidades translocales, si consideramos el conjunto de las sociedades locales desplegadas espacialmente por las migraciones y la movilidad. El que la mayoría de los mapuches -e indígenas en Chile- se radiquen en medios urbanos, pueblos y otras áreas rurales distintas de sus localidades de origen podría tratarse de un fenómeno de desarraigo a través de las emigraciones o incluso, pura y simplemente, de migraciones definitivas. Bajo este criterio, los indígenas salen presionados por restricciones y penurias para buscar nuevos horizontes, fuera y lejos de las comunidades de nacimiento. Como cualquier otro grupo de emigrantes definitivos, con el paso del tiempo van debilitando sus lazos con las comunidades maternas e integrándose a las realidades poblacionales de acogida. Esta imagen unidireccional y unimodal no es necesariamente falsa para una parte de los emigrados mapuches a Santiago, a Magallanes o a Neuquén, pero sí claramente insuficiente para representar las direcciones y modalidades que asume hoy la dinámica del desplazamiento indígena más allá de las fronteras de los asentamientos tradicionales. Por lo demás, ni siquiera hace justicia a las primeras etapas de las migraciones mapuches, hacia mediados del siglo XX y las dos décadas posteriores, al hacer invisible las de retorno (las femeninas, por ejemplo, de larga vigencia en este pueblo). Ello obliga a reconsiderar la migración y la diversidad de formas de movilidad como un simple y definitivo desarraigo de lo rural. Con la salida se abren posibilidades tanto para la absorción de los inmigrantes en las poblaciones, periferias urbanas y nuevas áreas rurales del país, como para la redefinición de las relaciones de los individuos, familias y grupos con las localidades indígenas rurales y al interior de éstas.

En efecto, las formas en que se producen los desplazamientos indígenas están cambiando. $\mathrm{Al}$ contrario de lo que podría pensarse, también proveen condiciones que favorecen la reproducción de redes sociale ${ }^{12}$ y corrientes de influencia de doble sentido. Proporciona esas posibilidades el acceso

12 Genéricamente, el sistema de relaciones sociales que sostienen individuos u hogares 
cada vez más expedito a medios de transporte y comunicación, lo que incide en un mayor dinamismo y complejidad del movimiento. Migraciones definitivas, migraciones temporales, migraciones de retorno, desplazamiento y movilidad fluidos, comunicaciones cotidianas entre familiares, vecinos y amigos dispersos en la geografía nacional encuadran hoy la interacción social planteada desde marcos locales indígenas ${ }^{13}$. Individuos, unidades familiares y segmentos locales y fuera de lo local mantienen una fluida comunicación y relaciones, lo que representa un dato relevante acerca del marco social en que se desarrollan los desplazamientos indígenas en el presente, algo bastante diferente a la pura emigración definitiva. Este patrón de movilidad más dinámico y complejo, así como algunas de sus implicaciones sociales y culturales se ponen en evidencia a partir del caso estudiado que detallamos más abajo ${ }^{14}$.

\section{LA COMUNIDAD DE ESCORIAL, UN EJEMPLO MAPUCHE DE TRANSLOCALIZACIÓN}

a) Los desplazados de la tierra mapuche y la búsqueda de la vida a través de la movilidad y la emigración

El estudio que sustenta estos análisis consideró trabajo de campo en una comunidad mapuche de la precordillera andina de la Araucanía ${ }^{15}$, tanto en su asentamiento rural como en sus segmentos translocalizados (urbanos o en otros sitios no urbanos) en relación con los rurales. En los faldeos del Volcán Llaima y en el camino que conduce al Parque $\mathrm{Na}$ cional Conguillío (comuna de Melipeuco, provincia de Cautín) radica un grupo de familias mapuche

13 O no locales, si acaso han ocurrido fenómenos de deslocalización (abandono de la localidad), de lo que existirían ejemplos en la zona aymara.

14 En el mismo sentido se orientan los resultados de un reciente estudio acerca de la ruralidad y la vida rural en Chile, intensamente transformada en relación al pasado. Se transita propiamente por "nuevos caminos": "hasta hace poco, la distancia, el tiempo de las comunicaciones y las conexiones entre lugares y actividades formaban un todo que definía al territorio rural como uno aislado, distinto y vuelto sobre sí mismo. Pero las distancias se han acortado, los tiempos se han reducido y los vínculos se han estrechado" (PNUD, 2008:37)

15 Además de una aymara y otra atacameña, por el interés comparativo de la investigación. derivadas de una línea parental de base de apellido Melivilu ${ }^{16}$. A este grupo de familias se le conoce en la comuna como localidad Escorial y a la Comunidad Indígena que hoy los organiza como Comunidad Melivilu-Melirayén. Los primeros antecesores provienen de la zona de Maquehua, de los terrenos en que se encuentra el aeropuerto de la ciudad de Temuco, la capital regional. Los Ancavil y Curín son descendientes de mujeres Melivilu que se emparejaron con hombres de ese apellido en Maquehua y que no residieron en las comunidades de los padres de sus hijos, como es la norma tradicional mapuche, sino que optaron con ellos por ser radicadas en Escorial. Lo mismo con Pinilla y Durán. Las familias Calfullán son originarias de las vecindades, incorporándose a Escorial mediante la compra de terrenos a otra familia mapuche descendiente de los primeros instalados.

Hacia finales de la década de 1920 se determinó la expropiación de los terrenos en que más tarde se construyó el aeropuerto de Temuco y para su erradicación se procedió a tratativas con las familias mapuches residentes. Su desplazamiento del lugar no se hizo efectivo sino hasta varios años más tarde, a inicios de la década de 1940. Se permutaron las tierras mapuches afectadas por otras fiscales en distintos sitios de la provincia. A dos de los grupos se les entregó tierras en la cordillera andina, correspondiendo a algunos de los Melivilu terrenos en el área de Escorial. Una de las familias Melivilu se limitó a vender las tierras a otros mapuches del sector y nunca se radicaron. La tierra prometida no fue la que encontraron ya que los bosques del lugar se encontraban con la mejor madera ya explotada y los campos se encontraban todavía incultos para los cultivos. Las comunicaciones eran difíciles en aquella época. Se disponía apenas de un camino de carreta hasta Cunco, donde se podía tomar ferrocarril a Temuco.

El campesinado indígena de la zona mantiene una dotación de recursos de tierra, madera, ganado, aguas y leña relativamente mejor que otras zonas mapuches, la del secano interior de Malleco sin ir más lejos. De todos modos y por poco que crecieran las familias los medios productivos y de vida se fueron haciendo insuficientes. Estos mismos fueron deteriorándose progresivamente por el

16 A los que se suman Ancavil, Curín, Pinilla, Durán y Calfullán. 
corte excesivo de árboles, la pérdida de fertilidad de la tierra y ausencia de labores de mejoramiento productivo (como riego, fertilización, empastadas, manejo forestal) en una escala suficiente. Como con todo el campesinado del sur de Chile, el de la precordillera andina de Cautín y el mapuche en particular, una salida a la pobreza consistió en el trabajo asalariado temporal o permanente. Este lo encontraron a veces en la misma zona (en fundos y aserraderos). Pero ello no se mantuvo en el tiempo. Luego de los convulsionados años de la década de 1970 los fundos se reconvirtieron productivamente y en lo sucesivo contrataron un mínimo de mano de obra. Esto concuerda con el agotamiento de los productos forestales de la zona, la prohibición de la corta de araucarias (Araucaria araucana), la obligación de planes de manejo forestal, el cierre de los aserraderos tradicionales y el cambio tecnológico en la producción de madera. Desde hace ya décadas que una comuna de extrema pobreza como Melipeuco ofrece poco en materia de empleo remunerado. Con todo, para los miembros de Escorial la vecindad a un parque nacional muy concurrido en los meses de verano les da oportunidades para el trabajo en los servicios al turismo y la venta de algunos productos y alimentos.

Otra salida a la que se acudió es la movilidad laboral y las migraciones definitivas. En la década de 1960 varias mujeres jóvenes del lugar se desplazaron a ciudades intermedias y grandes, especialmente la capital, y se ocuparon en servicios domésticos. Unas han retornado, pero la mayoría se quedó en Santiago perdiéndose paulatina los contactos con el sur de Chile. Los hombres, a veces con sus familias, han salido a Santiago, otros se han redistribuido en el área y unos cuantos se han dirigido al Neuquén. Especialmente desde la década de 1970, numerosos trabajadores de la zona, entre ellos los de Escorial, encontraron en esta provincia argentina empleo en labores forestales (la explotación de bosques en áreas cordilleranas cercanas, como la de Moquehue) y como peones agrícolas, obreros de la industria de la fruta y trabajadores de la construcción en Neuquén y el valle del Rio Negro. Otros sitios de destino de hombres y mujeres mapuches de Escorial fueron Centenario y San Martín de los Andes:

Después estuve p'acá pa' este otro lado, para el lado de Catrilelfu, una parte también que trabajaba yo volteando madera. Ya ahí después me fui pa' Argentina, veinte años tenía cuando me fui pa' Argentina. Me fui con mis papeles de aquí, saqué papel de antecedentes, pedí el salvoconducto, llevé papel de vacuna y mi carnet. Esos tres papeles pedían... Me fui a Neuquén. Trabajé en las chacras, en la cosecha de frutales, a trato. De la manzana se trabaja la Granny Smith, la Deliciosa, la otra, hay otra, la Fuji. Se trabaja la pera también, el durazno y otras frutas que se dan para allá nada más. La ciruela. Después trabajaba en el invierno en la poda de frutales, daba vuelta el año trabajando. Estuve cinco años, (durante los cuales) no vine nunca para acá. Me vine porque no tenía mis documentos argentinos, y por eso nos echaron los mismos milicos de allá. No me pedían a mí, porque yo trabajaba siempre en las chacras. Lo único es que renovaba mi tarjeta que llevaba de aquí de entrada, cuando vencía la renovaba, y con eso trabajaba ${ }^{17}$.

Antes nosotros íbamos a Moquehue, yo iba, no tenía ni un certificado de nacimiento... andaba trayendo. Me iba allá y trabajaba. Llegábamos caminando nosotros y creían que éramos de allá. Nosotros nos íbamos caminando, con Fernando iba. A caballo demoraban once horas, nosotros demorábamos ocho horas, porque nosotros conocíamos toda la cordillera y pasábamos la cordillera. Cuando fue el conflicto del '78, el Canal del Beagle, nosotros estábamos en Moquehue, puh. Chuta, estábamos ahí sin documentos, sin ni una cosa. Decían que estaban los milicos ahí en la frontera: nosotros no veíamos a nadie, ni milicos chilenos ni argentinos, no había nadie. Yo trabajaba más en un vivero, pero había unos agrónomos que eran chilenos, así que nosotros era llegar allá no más. Íbamos a estar todo el verano, después volvíamos. Era bueno ${ }^{18}$.

$\mathrm{El}$ atractivo del país vecino no se limitaba a la obtención relativamente fácil de trabajo mejor remunerado. También las condiciones laborales y las relaciones entre patrones y empleados se reconoce que son de una calidad poco conocida en la Araucanía:

La patrona (de Ana Isabel) era muy buena. Era la empleada y la patrona le servía. Se hacía la enferma, tenía vergüenza de comer junto con los patrones. ¿QQué te puedo preparar, Anita?', le

17 Entrevista a don Manuel Nahuelpán Melivilu. Escorial, 10 de junio de 2008.

18 Entrevista a don Luis Emilio Ramos Huina. Temuco, 25 de noviembre de 2008 
decía la jefa. Cuando se enfermaba la iba a dejar a la casa. No, si buena jefa le tocó. ${ }^{19}$

Tres tipos de migración son distinguibles: estacional (durante el periodos de cosecha en el valle del Río Negro); semipermanente (durante varios años, trabajando en invierno en labores de poda o como cuidadores de chacras, parcelas y sitios urbanos, pero regresando cada dos o tres años a Escorial por una temporada y luego reiniciando un nuevo ciclo), y definitivas (fundando familias en Argentina y cuyos hijos se incorporan a un mucho más amplio repertorio de ocupaciones).

Una oleada de traslados a Argentina se produjo con posterioridad al golpe militar, por razones económicas y también políticas. El cierre de algunos aserraderos fiscales, el inicio de la contrareforma agraria y las persecuciones a militantes y simpatizantes de izquierda o a integrantes de familias con detenidos desaparecidos impulsó a un numeroso contingente de trabajadores y campesinos, mapuches -algunos de Escorial- y no mapuches a cruzar la frontera:

Nosotros empezamos a irnos de a uno, de a uno, de a uno. La María es la que se fue primero, la llevó una tía, la Victorina. El '74, en marzo, la llevó, porque en Moquehue, en Argentina, necesitaban una empleada, ahí la llevó de empleada, pa' que trabaje. Entonces, de ahí encontró un joven y con él vive ahora. La otra después se casó el '76 parece, se fue también. Después José se fue, la María lo mandó a buscar, que vaya a trabajar, acá no había trabajo. Después ésta, a los 21, la María la mandó a buscar. De ahí empezaron éstos. Enferma una vez me llevaron: no me gustó nada la Argentina. Después dije yo: 'bueno'. Y éste me escribía que me vaya, que me vaya, que me vaya. Terminó el Cuarto Medio ésta y ya partimos. Me fui a Centenario. Le dejé el campo arrendado a Sergio Vega. ${ }^{20}$

Con el paso de los años se retomaron contactos con la localidad de origen, que se mantienen hasta la actualidad. En algunos casos se dieron retornos parciales aprovechando franquicias económicas (subsidios a la vivienda o pensiones de reparación).

Más recientemente, la crisis argentina de inicios de la presente década y el cambio monetario desfavorable disminuyeron el interés por Argentina y reforzaron la

19 Entrevista a doña Elena Huina Llancumil. Temuco, 25 de noviembre de 2008.

20 Entrevista a doña Elena Huina Llancumil. Temuco, 25 de noviembre de 2008. salida a la zona central del país, dirigiéndose al circuito de la fruta de la región central y a los trabajos temporales en la construcción. La migración definitiva tampoco ha cesado. Algunas pautas son similares respecto de las migraciones más tempranas y aquellas que se dirigieron a Argentina. En particular el traslado encadenado o "por arrastre" de familiares, amigos y conocidos. La percepción de la calidad de las relaciones laborales y trato no es, sin embargo, la misma respecto de lo que dejaron en el país trasandino.

Las migraciones y la movilidad son ya por décadas un componente importante de la vida económica mapuche de la comuna y Escorial. Las redes sociales tejidas en su transcurso permiten sostener nexos activos entre integrantes rurales en la localidad de origen, aquellos en situación de translocalización y aquellos que transitan entre lo uno y lo otro. Nutren esos nexos la comunicación periódica, los tratos económicos (custodias, medierías), las visitas ocasionales en uno y otro sentido, el intercambio de algunos bienes, el traspaso de información sobre oportunidades laborales, la solidaridad ante penurias y desgracias, etc. Esas redes progresivamente se amplían hacia nuevas relaciones en los lugares de destino (espacios de trabajo y residencia). Pero salvando casos individuales, no se desarrollan redes étnicas (con otros mapuches de Neuquén o en Santiago ${ }^{21}$. Estas permanecen en lo sustancial ligadas a los grupos locales de origen y translocales de destino

\section{LAS MIGRACIONES INTERNACIONALES MAPUCHES DESDE CHILE}

Las migraciones internacionales de indígenas a y desde Chile son frecuentes en la historia moderna del país. El norte del Chile es un área de afluencia de aymaras y quechuas de Bolivia desde finales del siglo $\mathrm{XIX}^{22}$. Indígenas andinos son también los emigrantes que desde Argentina ocupan con actividades ganaderas la cordillera occidental, y que dieron origen a la actual etnia coya. A su vez, desde finales del siglo

21 Ello explicaría el relativamente débil desarrollo de organizaciones mapuches en áreas de residencia no tradicional y, cuando se hacen presente, el marcado carácter familiar y parental del reclutamiento de sus miembros.

22 Fenómeno asociado a ciclos extractivos en la minería del salitre, cobre, azufre y bórax donde participan como asalariados. También, en una escala más modesta, la inmigración se dirige a la campesinización (a través de migraciones de relevo en los valles precordilleranos e incorporación a la agricultura comercial de Azapa, por ejemplo) (Gundermann, 2007). 
XIX se tiene conocimiento de la salida de obreros $y$ campesinos, mapuches o de origen mapuche muchos de ellos, a la Patagonia meridional y la Tierra del Fuego argentina, directamente o pasando por Magallanes ${ }^{23}$, pero también al Neuquén y Río Negro, buscando incorporarse a estas nuevas provincias como "colonos" o trabajadores en la economía ganadera de la región ${ }^{24}$. En el último medio siglo este flujo de chilenos (indígenas y no indígenas) no se ha detenido. Pero ahora no en demanda de tierras que colonizar, sino de trabajo en la industria forestal, agrícola, minera, de la construcción o los servicios del hogar. De hecho, en todo el sur de Chile se consideró por décadas a la Patagonia argentina como un destino laboral atractivo para complementar ingresos y, con el tiempo, intentar labrarse allá un mejor porvenir, o acumular recursos para invertirlos en el lugar de origen ${ }^{25}$.

Las emigraciones de mapuches desde la Araucanía y las regiones de los Ríos y los Lagos hacia el Neuquén y Río Negro que aquí analizamos son modernas ${ }^{26}$. Sus motivaciones son eminentemente

23 Desde mediados del siglo XIX, se han dirigido a Aysén, Magallanes, Tierra del Fuego y la región de Santa Cruz flujos de población procedente de la actual Región de Los Lagos, en especial de Chiloé insular y continental. El tercer cuarto del siglo XX sería un momento de activa afluencia de estos trabajadores a Magallanes (Martinic, 1999), en donde los chilotes de ascendencia mapuche-huilliche constituyen hoy el grueso del sustrato popular. Otra cosa es el reconocimiento étnico, un fenómeno de reciente aparición. Información complementaria sobre poblamiento e inmigraciones en la Patagonia meridional chilena y argentina puede encontrarse en Cepparo de Grosso, 1993, Martinic, 1996, Bona y Bilaboa, 2004.).

24 Por ejemplo, entre los documentos de la Comisión Parlamentaria de Colonización se menciona la memoria de 1905 del Cónsul en Neuquén Don Víctor Aquiles Bianchi, quien "calcula en 25.000 el número de chilenos de aquella región" (Congreso Nacional, 1912: 388). Se dice luego, que "la emigración ó, mejor dicho, la expulsión de chilenos y su refugio al oriente de los Andes, continuó en los años siguientes" (op. cit.:389).

25 Puede mencionarse también el exilio político mapuche producido durante el gobierno autoritario. Aunque pequeño en el número de personas, su aporte es relevante en la movilización étnica contemporánea.

26 En esta medida, no estamos hablando de los viajes al Puelmapu del pasado (siglo XIX en particular) de familias mapuches para engrosar las huestes de los grandes lonko de la pampa y beneficiarse de sus tratos y negocios con las autoridades del gobierno argentino o por vía de los malones. Tampoco de la gran movilidad, hacia Chile, pero también de vuelta en algunos casos, de mapuches desplazados por la Campaña del Desierto y la Pacificación de la Araucanía. Se trata de algo más reciente y en relación con sociedades y economías regionales modernas. económicas. Desde el punto de vista de las temporalidades implicadas, pueden ser coyunturales, estacionales o definitivas, ocurriendo en ciclos de corta, media y larga duración. Constatamos, asimismo, la existencia de ciclos e intensidades variables en los flujos de migración según los periodos históricos, los avatares de las economías nacionales y regionales y las oportunidades que ellos abren o cierran para los propósitos de movilidad y migración. Insistamos, todavía, en que participan en estos desplazamientos tanto campesinos como obreros, mapuches y no mapuches. La pobreza en la Araucanía y regiones adyacentes impulsa en distintas direcciones (Santiago, Concepción, la Patagonia chilena y argentina) a una parte de su población.

Quizá donde se constata de manera más característica la presencia de chilenos es en el trabajo en huertos frutales, chacarería y plantas procesadoras de frutas y zumo de Neuquén y Río Negro. A partir de 1960, la industria de la fruta experimentó una considerable ampliación e intensificación productiva y no pudo cubrir sus necesidades estacionales de mano de obra con personal local o de otras regiones de Argentina. La fuerza de trabajo chilena temporal o radicada establemente se hará desde entonces característica en esta actividad económica de nor Patagonia (Trpin, 2004: 47-64, y 2005)27. En las áreas urbanas, la participación de mujeres chilenas en el servicio doméstico y de sus compatriotas varones en las faenas de construcción es también notoria. Por otro lado, se ha podido observar una considerable presencia de trabajadores mapuches

27 Esta autora analiza lo que ella llama "una división "nacional" del trabajo" (p.63), en la que una persistente identificación nacional de los trabajadores en la industria de la fruta patagónica a menudo se prolonga hasta la o las generaciones siguientes a los emigrantes directos, a pesar de que legalmente son ya argentinos. Tanto por la propia fuerza de los sentimientos nacionales de los inmigrados, como por la existencia de fronteras sociales nacionalitarias (asociadas a la especialización chilena en ciertos tipos de trabajos asalariados no calificados y a la percepción argentina de que los chilenos ocupan ciertos nichos laborales), la definición de identidad colectiva más gravitante es la nacional. Hasta donde estamos informados, los emigrados mapuches a Argentina participan de este reposicionamiento de la identidad nacional en las regiones de destino, sin que la pertenencia indígena sea aquí socialmente relevante, como sí lo es en la Araucanía de origen. Destacamos con esto la contextualidad e historicidad de las identificaciones colectivas que se hacen socialmente significativas. 
provenientes de Chile en faenas de explotación forestal (tala, aserreo y plantación) en las cordilleras del Neuquén, especialmente durante las décadas de 1970 y 1980.

La Reforma Agraria en Chile (1964-1973) $y$, en especial, la llamada Contrarreforma del gobierno autoritario (1974-1980), desplazaron a mucha gente desde los campos del sur de Chile. La expansión forestal de los años ochenta del siglo recién pasado en las regiones del Biobío, Araucanía y Los Ríos; la crisis de la agricultura tradicional como consecuencia de la apertura chilena al mercado internacional de productos agrícolas y, al mismo tiempo, el cambio en las modalidades de articulación entre empresa agropecuaria y campesinado en el sur de Chile, estrecharon considerablemente las posibilidades de empleo $e$ ingresos de los mapuches y otros campesinos de la zona. La salida a la Argentina constituyó una válvula de escape a las penurias derivadas de la transformación de la economía agraria regional. No es ajena a esta búsqueda de nuevos horizontes la inseguridad por razones políticas que se vivía durante el gobierno autoritario.

Un momento especialmente propicio para la emigración estacional y la radicación estable en la Argentina tuvo lugar en el período en que, durante la administración de Menem, se mantuvo la paridad del peso con el dólar. El dinero ganado en ese país estaba sujeto a un cambio sumamente conveniente en Chile, mientras que el bajo salario básico y rural nacional no representaba un atractivo mayor que el de sostener la mera subsistencia. Si a lo anterior se agrega que en el sur de Chile la oferta de empleo se mantuvo relativamente deprimida, se completa el cuadro favorable a la búsqueda de trabajo en la Patagonia argentina para aquellos hombres y mujeres, mapuches y no mapuches, que estuvieran dispuestos a salir. Un factor relevante para el éxito de las iniciativas de traslado (estacional o de más largo plazo) se encuentra en la vigencia de redes sociales. Los parientes, amigos y conocidos en Argentina representan un capital social estratégico para la instalación, hospedaje, información sobre empleo, trámites migratorios, permisos de trabajo, maneras de permanecer en la informalidad, etc. Estas redes tienen décadas de existencia, ya que se fueron creando con los varios flujos y pulsaciones de migración chilena a la Patagonia argentina que, como hemos dicho, han tenido lugar desde mediados del siglo XX. Incluso en ausencia de vínculos de parentesco, amistad o comunalidad, un intenso y sostenido sentimiento de identidad nacional contribuye a reforzar los lazos de solidaridad y compromiso entre compatriotas.

La ulterior crisis argentina puso un freno a este proceso. La movilidad, estacional o no, y la emigración definitiva no se han detenido, pero los contingentes involucrados son mucho menores. Por lo demás, el sostenido crecimiento de la economía chilena y el alza de los salarios hacia mediados de la década de 1990 abrieron nuevas perspectivas para la fuerza laboral de las regiones del sur. El circuito del trabajo "temporero" de la fruta en la región agrícola comprendida entre el valle de Copiapó y el extremo norte de la Araucanía es hoy una de las alternativas de ingreso monetario más recurridas por los mapuches. Por otra parte, la expansión de la acuicultura en la zona de Los Lagos, Llanquihue, Chiloé insular y continental y Aysén atrae a trabajadores mapuches, entre otros del centro sur del país, como asimismo los elevados salarios que pueden obtenerse en las explotaciones mineras del norte. Estos destinos han venido a sumarse a aquellos históricos de la emigración mapuche, como la ciudad de Santiago ${ }^{28}$.

No puede desprenderse de lo anterior, sin embargo, que el sur de Argentina dejó de representar una región de interés para la movilidad y la migración de trabajadores desde el sur de Chile. Las economías campesinas e indígenas de esta zona son hoy estructuralmente dependientes de aportes monetarios externos (y subsidios estatales) y, en esa medida, seguirán buscando fuentes de ingreso favorables allí donde se encuentren, en tanto cuenten con los conocimientos y relaciones sociales indispensables para acceder a ellas. La actual detención del flujo hacia el sur de Argentina -e incluso parcial reflujo- es algo que puede cambiar en una próxima coyuntura.

28 Además de los resultados censales, una fuente indirecta de verificación de la emigración definitiva es la presencia y el paulatino aumento de organizaciones mapuches (Comunidades y Asociaciones) en regiones que no constituyen áreas de residencia tradicional. 


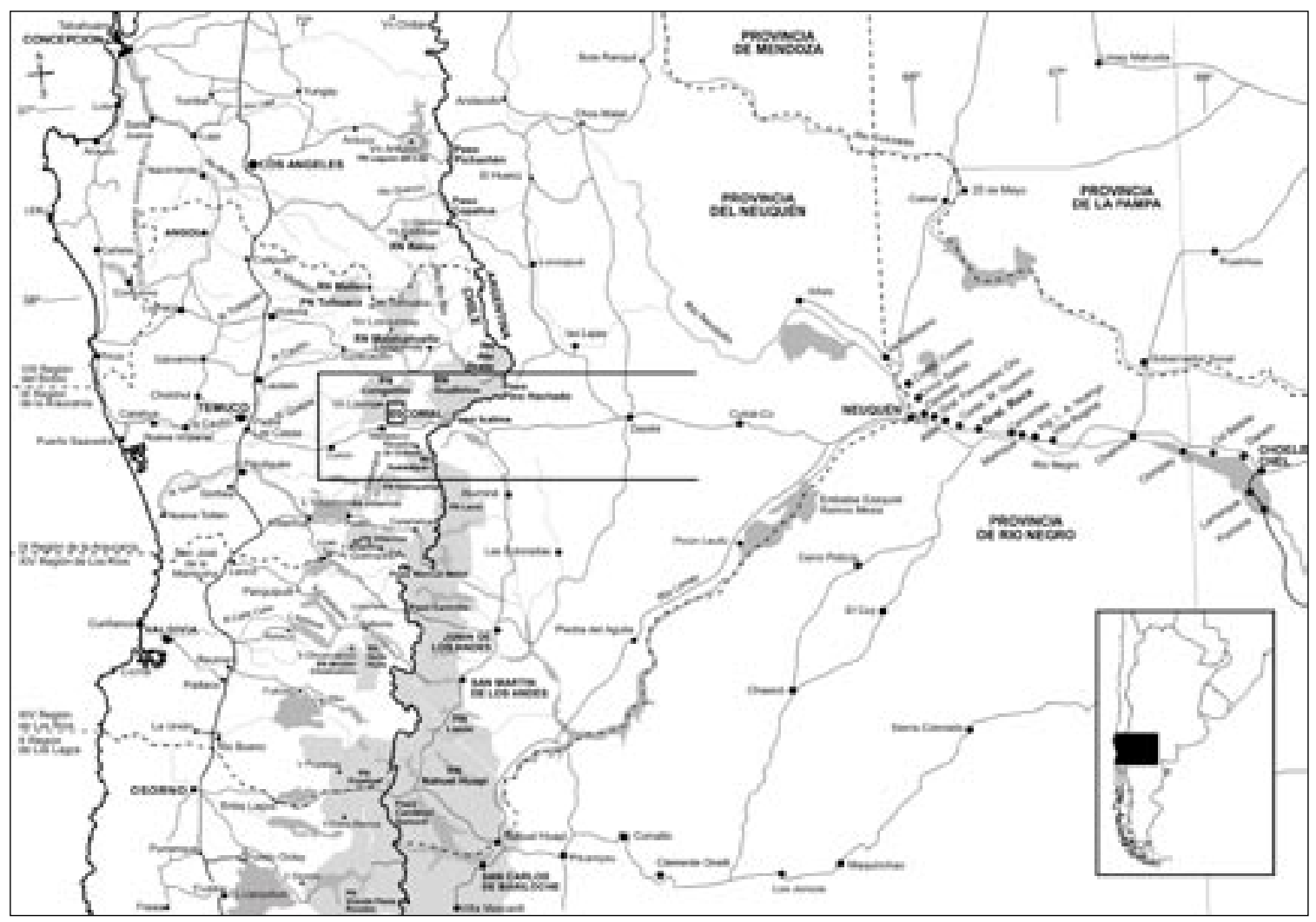

Área geográfica del estudio.

\section{CONCLUSIONES}

La literatura acerca de los pueblos indígenas de Chile y el estudio de casos, como el de Escorial, aportan evidencia para sostener que se ha llevado a efecto una fundamental redistribución espacial de su población durante el último medio siglo. Lo han hecho incorporándose a nuevas áreas rurales, pero sobre todo a centros urbanos de tamaño pequeño y mediano, o también a la Región Metropolitana de Santiago. Los mapuches, en particular, se han dispersado en un amplísimo radio: Magallanes por el sur; los centros mineros y urbanos del norte, en el extremo opuesto, y localidades de la Patagonia argentina, por el oeste. Son así partícipes del profundo cambio en los patrones de residencia, de vida $y$ trabajo que ha tenido lugar en Chile a partir de la segunda mitad del siglo XX, y que tiene sus raíces en la industrialización, el explosivo crecimiento urbano y las transformaciones en el agro.

Esa redistribución es específica a las regiones de pertenencia y a procesos de expansión econó- mica y modernización, pero también a realidades socioculturales propias de los pueblos originarios. El juego entre condiciones y factores internos y externos origina lo que hemos denominado pauta de integración, entendida como forma de articulación con la economía regional, nacional e internacional $y$, a la vez, como un sistema de relaciones inscriptas sobre espacios sociales mucho más distendidos que aquel formado históricamente por las políticas republicanas impuestas a las sociedades indígenas (en el caso de los mapuches, la "reducción" inserta en un sistema agrario mayor) ${ }^{29}$. Como ya hemos

29 El caso mapuche presenta una consistente unidad en los mecanismos de integración regional (incorporación a mercados urbanos y rurales de fuerza de trabajo principalmente en los rubros de la agricultura, las industrias panificadora y de la construcción, y servicios al hogar), pero a la vez una significativa heterogeneidad en los espacios regionales y nacionales en los cuales se materializa este patrón relativamente homogéneo (Concepción y Santiago, circuito de la fruta en el valle central, ciudades y pueblos del sur de Chile, Magallanes en el extremo sur del país y la Patagonia argentina). 
señalado, la pauta de integración regional mapuche está condicionada por la escasez de recursos, el deterioro productivo $y$, últimamente, por las transformaciones en la economía agraria regional (crisis de la agricultura tradicional, expansión forestal), lo que induce al traslado a centros urbanos, a cuyos mercados laborales suelen integrarse como trabajadores no calificados ${ }^{30}$. Con ello, la propia condición campesina de los mapuches queda en entredicho al aumentar considerablemente el acceso a fuentes no agrarias de ingresos, con un incremento correlativo de la movilidad espacial. Lo anterior provee condiciones para un cuadro de relaciones y flujos mucho más dinámico que en el pasado entre sujetos urbanos, rurales o fluctuantes entre lo urbano y lo rural. Así, la sociedad mapuche mantiene un anclaje menos intenso que antes en las condiciones rurales de vida y trabajo, disminuye su dependencia de recursos agrarios, desdibuja su perfil campesino y redistribuye sus contingentes en un área cada vez más extensa. A este conjunto de fenómenos lo denominamos postcomunalidad ${ }^{31}$. Se marca con ello una diferencia, un punto de inflexión en los procesos de modernización que inciden sobre los pueblos indígenas de Chile.

Paradojalmente, la mayor complejidad en la movilidad espacial indígena del presente tiene implicaciones que favorecen más que deprimen las relaciones y el intercambio indígena en los espacios de translocalización. Una de ellas es la refuncionalización de la comunidad de origen como espacio de repliegue económico y retiro de fuerza de trabajo, pero también como "base de opera-

30 Tal condición suele variar en las siguientes generaciones de las familias migrantes. Huelga decir que la categoría ocupacional y el nivel educativo no sólo influyen en la amplitud de las redes sociales a las que el sujeto se incorpora o construye en torno a sí, sino también en la posición (en sentido jerárquico) y el grado de influencia que puede alcanzar al interior de ellas.

31 A partir de su generalización, constituyen aspectos caracterizadores clave la movilidad espacial y residencial, la dispersión sobre una extensa subregión, la multi ocupación y los multi ingresos, la inestabilidad y precariedad de los empleos, así como la redefinición de la ruralidad y sus significaciones. En consecuencia, resulta incompleto apreciar la dinámica espacial indígena sólo como persistencia en la ruralidad y disolución de la identidad social de origen en los nuevos sitios de destino. Aunque tales fenómenos existen, proporcionan una descripción insuficiente de la movilidad y las relaciones que permanecen, se forman o cambian bajo los parámetros espaciales del presente. ciones" o "nave madre" para formas de movilidad estacional o migraciones de más largo aliento. Ello es coherente con la activa participación mapuche en mercados de trabajo interregionales. Incluso en el caso del sector mapuche todavía concentrado en la producción campesina, las localidades rurales se definen mejor como segmentos de un sistema de trabajo e ingresos más diversificado, que sólo como un recurso de seguridad social. Otra derivación es el cambio en las condiciones de comunicación, transporte y accesibilidad que facilitan la frecuencia de la interacción, directa o mediada por tecnologías. Una tercera, finalmente, es la significación que adquiere la comunidad local como el espacio de la "costumbre" (principalmente la religiosa) y, más recientemente, como el locus de la cultura étnica y la identidad ${ }^{32}$.

Las migraciones mapuches se han dirigido hacia diversos destinos, entre ellos la Patagonia argentina. La más temprana emigración campesino mapuche desde Chile fue protagonizada por chilotes que, desde la segunda mitad del siglo XIX se dirigieron a Magallanes y Aysén y, desde allí o directamente, a Santa Cruz y Chubut. Desde mediados del siglo recién pasado se agrega a estas corrientes tempranas el flujo de trabajadores mapuches y no mapuches procedentes de las regiones del Biobío, Araucanía, Los Ríos y Los Lagos -en especial de la zona andina fronteriza- hacia la región nor patagónica argentina (Río Negro y Neuquén). Las

32 Singularmente, para jóvenes nacidos y criados en ciudades como Santiago, Valparaíso o Concepción, cuyas familias llevan décadas de residencia urbana, y para los intelectuales indígenas que concentran sus esfuerzos en tareas de redescubrimiento y revitalización cultural. Las cada vez más frecuentes y variadas iniciativas en las que unos y otros interactúan con comunidades locales dan lugar al surgimiento de nuevas redes sociales, al interior de las cuales información e influencias circulan bi direccionalmente. También cabría considerar aquí las redes de visibilización y apoyo construidas por el movimiento mapuche de reivindicación de derechos territoriales y políticos, a través de las cuales, por una parte, integrantes de comunidades en conflicto han podido dar a conocer sus motivaciones y experiencias en Suiza (ante Naciones Unidas), Francia, España y Canadá, entre otros países y, por otra parte, observadores internacionales, cientistas sociales y simpatizantes del movimiento indígena procedentes de esos mismos países han tenido la oportunidad de visitar dichas comunidades. La idea de que la vida y la cultura mapuches se encarnan y concentran en sus comunidades rurales es especialmente enfatizada en estos intercambios translocales. 
oleadas de migración estacional, semipermanente o definitiva han alimentado una significativa presencia chilena en esas provincias, proporcionando a su economía fuerza de trabajo valorada por su tenacidad. En ciertos rubros de trabajo, como el de la fruticultura del valle del Río Negro o las faenas forestales en la cordillera andina argentina, representan el grueso de los trabajadores. La antigüedad de la experiencia chilota contrasta, también, con la migración mapuche a la Región Metropolitana, que se hace visible sólo a mediados del siglo XX y con la todavía más reciente masiva afluencia y a veces radicación de trabajadores mapuches en la región agrícola central ${ }^{33}$.

De todo ello no se ha eximido Escorial, como ya se señalara. Esta localidad precordillerana ejemplifica un caso de relocalización inicial en un área de montaña cuyos integrantes con el paso del tiempo empezaron a depender cada vez más de fuentes externas de ingresos, luego que la madera se explotara, la tierra perdiera fertilidad y la población creciera. Dada la relación de proximidad que mantienen con Neuquén y Rio Negro las comunas de la Araucanía Andina en la provincia de Cautín, el campesinado de la zona -mapuches incluidos-amplía la cobertura de sus desplazamientos para considerar, además de la propia Araucanía y Santiago, una región argentina limítrofe. De esta manera, las comunidades mapuches andinas, más que las del valle central y de la costa pacífica, se involucran en traslados estacionales y emigraciones a la Patagonia argentina septentrional. Facilidades de traslado y redes sociales inter fronterizas constituidas previamente permiten entender esta tendencia. Por ello es que una comunidad como Melivilu-Melirayén presenta relaciones activas con Argentina, mientras que en Maquehua, su más temprano lugar de origen en el valle central, ello es más irregular y difuso. No obstante, una situación de proximidad fronteriza y una red de lazos sociales vigentes no son suficientes si acaso los mercados de fuerza de trabajo nacionales $e$ internacionales dejan de proveer oportunidades de inserción. Su amplitud o estrechez, el tipo de demanda laboral que gestan, los ciclos económicos

33 Para complicar más las cosas, la expansión de la industria acuícola en Llanquihue, Chiloé y Aysén atrae trabajadores desde regiones septentrionales, la Araucanía de manera destacada, y entre ellos, un cierto número de personas mapuches. o las relaciones entre los países son decisivos para dar vigencia y vitalidad a esas redes sociales. De allí que la condición fronteriza y las relaciones creadas a través de la frontera como factor potencial para la emigración, la translocalización y la incorporación a la economía formal o el acceso a mercados, sean también relativos a escenarios y procesos más amplios.

\section{BIBLIOGRAFÍA CITADA}

ABARCA, GERALDINE. 2002. Mapuches de Santiago. Rupturas y continuidades en la recreación de la cultura, Revista de la Academia (7):105-120, Santiago.

ANCÁN, JOSÉ. 1994. Los urbanos, un nuevo sector dentro de la sociedad mapuche contemporánea. Pentukún (1): 5-15, Temuco.

ANCÁN, JOSÉ Y MARGARITA CALFÍO. 1999. El retorno al país mapuche. Liwen (5): 43-79, Temuco.

ARAVENA, ANDREA. 2000. La identidad indígena en los medios urbanos. Procesos de recomposición de la identidad étnica mapuche en la ciudad de Santiago. Lógica mestiza en América, Boccara, Guillaume y Silvia Galindo (Editores.), pp. 165-199, Universidad de La Frontera, Temuco.

ARAVENA, ANDREA. 2002. "Los mapuche - warriache: procesos migratorios contemporáneos e identidad mapuche urbana. Colonización, resistencia y mestizaje en las Américas, Siglos XVI-XX, Guillaume Boccara (Editor), pp. 359-385, Abya Yala, Instituto Francés de Estudios Andinos, Quito - Lima.

ARAVENA, ANDREA. 2003. El rol de la memoria colectiva y de la memoria individual en la conversión identitaria mapuche. Estudios Atacameños (26):89-96. San Pedro de Atacama.

BABAROVIC, IVO, PILAR CAMPAÑA, CECILIA DÍAZ Y ESTEBAN DURÁN. 1997. Campesinado mapuche y procesos socio-económicos regionales. Documento de Trabajo №34, Grupo de Investigaciones Agrarias, Academia de Humanismo Cristiano, Santiago de Chile.

BENGOA, JOSÉ. 1985. Historia del pueblo Mapuche, siglos XIX y XX. Ediciones SUR, Santiago de Chile.

BENGOA, JOSÉ. 1996. Población, familia y migración mapuche. Los impactos de la modernización en la sociedad mapuche 1982-1995. Pentukún (6): 9-29, Temuco.

BENGOA, JOSÉ . 1997. La población de las comunidades mapuches de Chile. Los mapuches. Comunidades y localidades en Chile, Instituto Nacional de Estadísticas - Sur Ediciones, pp.9-27, Santiago de Chile. 
BENGOA, JOSÉ. 2000. Políticas públicas y comunidades mapuches: del indigenismo a la autogestión. Perspectivas, vol.3 (2): 331-365, Santiago de Chile.

BENGOA, JOSÉ Y EDUARDO VALENZUELA. 1982. Economía mapuche. Pobreza y subsistencia en la sociedad mapuche contemporánea. PAS, Santiago de Chile.

BONA, AIXA Y JUAN BILABOA. 2004. "Las relaciones argentino-chilenas en el extremo austral 1930-1955. Magallania (32):15-21, Punta Arenas.

CONGRESO NACIONAL. 1912. Comisión Parlamentaria de Colonización. Informe, Proyectos de Ley, Actas de las Sesiones y otros antecedentes. Sociedad Imprenta y Litografía Universo", Santiago de Chile.

CUMINAO, CLORINDA Y LUIS MORENO. 1998. El Gijatun en Santiago una forma de reconstrucción de la identidad Mapuce. Tesis de Licenciatura, Universidad Academia de Humanismo Cristiano, Santiago de Chile.

CEPPARO DE GROSSO, MARÍA EUGENIA. 1993-1994. Hacia la búsqueda de relaciones más complejas entre redes y asentamientos de dos espacios australes fronterizos, en Anales del Instituto de la Patagonia vol. 22:77-90, Punta Arenas.

CURIVIL, RAMÓN. 1999. Los cambios culturales y los procesos de re-etnificación entre los mapuches urbanos: un estudio de caso. Tesis de maestría en Ciencias Sociales, Universidad Academia de Humanismo Cristiano, Santiago de Chile.

FOERSTER, ROLF. 1983. Martín Painemal. Vida de un dirigente mapuche.Grupo de Investigaciones Agrarias GIA, Santiago.

GISSI, NICOLÁS. 2001. Asentamiento e identidad mapuche en Santiago: entre la asimilación (enmascaramiento) y la autosegregación (ciudadanía cultural). Tesis de Magíster, Instituto de Postgrado en Estudios Urbanos y Territoriales, Universidad Católica de Chile, Santiago.

GONZÁLEZ, HÉCTOR. 1996. Características de la migración Campo-Ciudad entre los Aymaras del Norte de Chile. Corporación Norte Grande, Serie Documentos de Trabajo, Arica.

GONZÁLEZ, HÉCTOR. 1997a. La inserción económica de los migrantes Aymara en la Ciudad: El Trabajo como empresa familiar y la Reproducción Cultural. Actas Segundo Congreso Chileno de Antropología, Tomo I, pp. 315-324, Santiago.

- 1997b. Economía y uso del espacio en la sociedad Aymara actual. Actas Segundo Congreso Chileno de Antropología, Tomo 2, pp.567-579, Santiago.
GUNDERMANN, HANS. 2007. Pueblos indígenas en la región atacameña moderna. Historia Indígena (10): 63-87, Santiago.

GUNDERMANN, HANS Y HÉCTOR GONZÁLEZ. 1995. Tierra, agua y sociedad atacameña, un escenario cambiante. Agua, ocupación del espacio y economía campesina en la región atacameña, Pierre Pourrut y Lautaro Nuñez (Editores), pp. 78-106. Universidad Católica del Norte - Institut Français de Recherche Scientifique pour le Développement en Coopération, Antofagasta.

GUNDERMANN, HANS Y HÉCTOR GONZÁLEZ. 2008. Sociedades indígenas y conocimiento antropológico. Aymaras y atacameños de los siglos XIX y XX. Chungara, Revista de Antropología Chilena 41(1):113-164.

GUNDERMANN, HANS Y HÉCTOR GONZÁLEZ. 2008. Pautas de integración regional, migración, movilidad y redes sociales en los pueblos indígenas de Chile. Revista Universum (23) vol. 1, pp. 82-115.

GUNDERMANN, HANS, JORGE IVÁN VERGARA Y ROLF FOERSTER. 2005a. Contar a los indígenas en Chile. Autoadscripción étnica en la experiencia censal de 1992 y 2002. Estudios Atacameños (30): 91-115.

GUNDERMANN, HANS, JORGE IVÁN VERGARA Y ROLF FOERSTER. 2005b. La auto adscripción étnica de los pueblos andinos en Chile analizada a través de las cifras censales de 1992 y 2002. Revista Andina (41): 9-61.

INSTITUTO NACIONAL DE ESTADÍSTICAS, INE. 2003. Censo 2002. Síntesis de resultados. INE, Santiago de Chile.

INSTITUTO NACIONAL DE ESTADÍSTICAS INE Y PROGRAMA ORÍGENES MIDEPLAN - BID. 2005. Estadísticas Sociales de los Pueblos Indígenas en Chile, Censo 2002, INE, Santiago de Chile.

KEARNEY, MICHAEL. 1996. Reconceptualizig the Peasantry. Anthropology in Global Perspective. Westview Press, Colorado, USA.

KELLNER, ROGER. 1994. The Mapuche during the Pinochet Dictatorship (1973-1990). Tesis Doctoral, Universidad de Cambridge, Inglaterra.

MALLON, FLORENCE. 2004. La sangre del copihue. La comunidad mapuche de Nicolás Ailío y el Estado Chileno 1906-2001, LOM Ediciones, Santiago de Chile.

MARTINIC, MATEO. 1996. Contribución magallánica a la formación y desarrollo de la sociedad santacruceña: corrientes inmigratorias. Anales del Instituto de la Patagonia (24): 5-10, Punta Arenas.

MARTINIC, MATEO. 1999. La inmigración chilota en Magallanes. Apreciación histórica sobre sus causas, características y consecuencias, en Anales del Instituto de la Patagonia, Serie Ciencias Sociales, pp.27-47, Punta Arenas. 
MC FALL, SARA. 1998. Keeping Identity in its place. Cultura and politics among the mapuche in Chile. Tesis de Doctorado en Antropología, Universidad de Oxford, Inglaterra.

MUNIZAGA, CARLOS. 1961. Estructuras transicionales en la migración de los Araucanos de hoy a la ciudad de Santiago de Chile. Notas del Centro de Estudios Antropológicos $\mathrm{N}^{\circ} 6$, Publicación $\mathrm{N}^{\circ} 12$, Santiago de Chile.

PROGRAMA DE LAS NACIONES UNIDAS PARA EL DESARROLLO PNUD. 2008. Desarrollo humano en Chile rural. Seis millones por nuevos caminos. PNUD, Santiago de Chile.

STUCHLIK, MILAN. 1999. La vida en mediería. Mecanismos de reclutamiento social de los mapuches. Soles ediciones, Santiago de Chile.
TRPIN, VERÓNICA. 2004. Aprender a ser chilenos. Identidad, trabajo y residencia de migrantes en el Alto Valle del Rio Negro. Antropofagia, Buenos Aires.

TRPIN, VERÓNICA. 2005. Migrantes chilenos en la fruticultura del Rio Negro: disputas por el trabajo y los beneficios sociales. 7mo Congreso Nacional de Estudios del Trabajo, Buenos Aires. http://www.aset.org.ar/congresos/7/15007.pdf (consulta del 8/10/2008)

VALDÉS, MARCOS. 1997. Migración mapuche y no mapuche. Ethnos (1). Facultad de Ciencias Sociales, Universidad de Chile. http://www.csociales.uchile.cl/publicaciones/biblioteca/docs/ethno/ethno1.pdf (consulta del 8/10/2008).

VALENZUELA, RODRIGO. 1995. La población indígena en la Región Metropolitana. Corporación Nacional de Desarrollo Indígena CONADI, Santiago. 
H. GUNDERMANN, H. GONZÁLEZ Y L. DE RUYT 